Article

\title{
Woody Biomass Mobilization for Bioenergy in a Constrained Landscape: A Case Study from Cold Lake First Nations in Alberta, Canada
}

\author{
Nicolas Mansuy ${ }^{1, *}$, Diana Staley ${ }^{2}$ and Leila Taheriazad ${ }^{3}$ \\ 1 Natural Resources Canada, Canadian Forest Service, Northern Forestry Centre, 5320122 st., \\ Edmonton, AB T6H 3S5, Canada \\ 2 Dianalytics, Edmonton, AB T6H 3S5, Canada; diana.staley@dianalytics.ca \\ 3 Department of Earth and Atmospheric Science, University of Alberta, Edmonton, AB T6G 2E3, Canada; \\ taheriaz@ualberta.ca \\ * Correspondence: Nicolas.mansuy@canada.ca; Tel.: +1-825-510-1238
}

Received: 10 November 2020; Accepted: 22 November 2020; Published: 28 November 2020

\begin{abstract}
Wood-based bioenergy systems developed and managed by Indigenous communities can improve their ability to thrive and grow economically and socially and improve their resource-based decision-making processes. In this study, we collaborated with Cold Lake First Nations (CLFN), a community located in Northern Alberta, Canada, to investigate the opportunities and challenges of biomass mobilization from different feedstocks. Based on remote sensing and ground data, harvest residue and fire residue feedstocks were identified within the boundaries of the community and inside a radius of $200 \mathrm{~km}$ at 18 and 39 oven-dry metric tonnes (odt)/ha, respectively. CLFN also received woody biomass from local oil and gas producers that operate in their traditional territory, which is estimated at 19,000 odt/year. Despite being abundant, the woody biomass is difficult to access due to the extensive human footprint that surrounds the area and constrains the landscape. In terms of greenhouse gas (GHG) mitigation, the potential also appears limited because the community has access to natural gas at a competitive and stable price, unlike off-grid communities. In terms of cost savings, the low oil and gas prices make the biomass resources (pellets) less competitive to utilize than the natural gas that is available in the community.
\end{abstract}

Keywords: bioeconomy; carbon mitigation; harvesting residues; Indigenous community; pellet

\section{Introduction}

In the face of climate change, the United Nations Declaration on the Rights of Indigenous Peoples (UNDRIP) outlines that the consultation of Indigenous communities is crucial to the rapid development of renewable energy projects [1]. These projects have the potential to deliver tangible benefits to a community's well-being, such as establishing more reliable clean energy systems and securing long-term financial benefits, as well as helping Indigenous communities move toward energy autonomy.

Indigenous community leadership and stewardship are expected to play an integral role in Canada's transition to the low carbon economy [2,3]. According to the 2016 Census [4], more than 1.67 million people in Canada identified themselves as an Indigenous person, or $4.9 \%$ of the total Canadian population. Northern and Indigenous communities, however, face many opportunities and challenges as Canada shifts toward a cleaner energy future. For example, more than $70 \%$ of remote and Indigenous communities are completely powered by diesel generators. The burning of these fossil fuels has negative impacts on human health and well-being and on the environment, as well as contributes to climate change. In some cases, community reliance on diesel-based electricity also limits their ability to thrive and grow, exacerbating difficult economic conditions and social inequalities [5]. 
Over the past few years, Canadian federal government funding has helped shift the clean energy landscape by supporting wood-based bioenergy projects in remote Indigenous communities as a means to reduce community reliance on diesel fuel for heat and power and to help reduce greenhouse gas (GHG) emissions [6]. In addition to the development of clean energy systems, energy independence, economic development, revenue and job generation, and community resilience are often goals mentioned when remote Indigenous communities discuss their plans for an energy transition [7].

However, many of these socio-economic and environmental benefits may be far from reach because the wood-based bioenergy supply chain is generally complex and not yet mature in Canada [8,9]. The required upstream processes related to biomass mobilization and the assessment of the wood supply chain have not been fully understood in Canada and the lack of understanding could jeopardize these initial wood-based clean energy investments. Some of the challenges identified by Indigenous communities to utilize and mobilize biomass include securing stable and sustainable wood supply chains, integrating the development of biomass harvesting practices that are compatible with the energy needs and the land uses of the communities, and sourcing sufficiently skilled staff with resources to support community-based decision-making processes [10,11].

While recent studies have documented the development of bioenergy programs as a means to support reconciliation with the Indigenous peoples in Canada [12,13], this study does not address this issue. Meanwhile, this study is relevant and innovative for supporting the development of community-based bioenergy, as well as for increasing Indigenous participation in forestry-related opportunities, businesses, and governance.

This study aimed to provide technical support to Cold Lake First Nations (CLFN) to quantify the biomass available for bioenergy purposes on its land. The community is located in Northern Alberta, Canada, and has recognized that there is a need to diversify their economy in order to bring stable incomes to the community. The CLFN leadership has instructed its Economic Development department to assist the Nation to explore new economic opportunities that are not fully reliant on the oil and natural gas sector, which is the primary driver of the economy in the region. The bioeconomy, including the creation of value-added forestry products, as well as bioenergy production, are alternatives that the CLFN is considering. To enter into the bioeconomy, CLFN needs a clear understanding of its local feedstock supply in order to start the first phase of project development. Therefore, this collaborative project has been recognized as an essential first step toward identifying CLFN's ability to participate in the bioeconomy and will be an important input into their low carbon economy planning in the future.

\section{Cold Lake First Nations: Land, Culture, History, and Socio-Economical Values}

The traditional land of CLFN is located in the Lower Athabasca Region, which is in the northeastern part of Alberta $\left(54^{\circ} 27^{\prime} 46^{\prime \prime} \mathrm{N}\right.$ and $\left.110^{\circ} 10^{\prime} 37^{\prime \prime} \mathrm{W}\right)$ and covers about 2 million ha. As shown in Figure 1, the CLFN traditional land that is located within Alberta is about 1.08 million ha, and the land on the Saskatchewan side is about 0.95 million ha. The traditional land of CLFN extends across the provinces of Manitoba and Alberta, but the study focused primarily on the region in Alberta (Figure 1a). The region is relatively flat with an elevation of $650-700 \mathrm{~m}$ and the climate is subpolar continental humid, with temperatures typically varying from $-19{ }^{\circ} \mathrm{C}$ to $24^{\circ} \mathrm{C}$, and is rarely below $-32{ }^{\circ} \mathrm{C}$ or above $29^{\circ} \mathrm{C}$.

Based on the national ecological framework for Canada, CLFN is located in the Boreal Plains ecozone. This area has significant overlap with the Central Mixedwood Natural Region, which has deciduous forests and coniferous stands that are located in the uplands, as well as wet and poorly drained bogs and fens in the lowland areas [14]. The boreal mixed-wood forest in this area is comprised of different stand compositions. More than 30\% of CLFN's forested areas are covered and dominated by deciduous species, such as trembling aspen, poplar birch, and paper birch. Coniferous species, such as white spruce, black spruce, tamarack, jack pine, and balsam fir, occupy about $56 \%$ of the region.

Cold Lake First Nations is part of the larger Dene Suline Nation, which contains three main tribes including Yellowknife, Churchill, and Cold Lake. CLFN currently has 1395 residents living 
on-reserve with an average annual population growth rate of $14 \%$ (2006-2016). CLFN is a community with a strong background in business ownership and economic development as a means to enhance community well-being. Approximately $62 \%$ of band members living on-reserve work in the oil and gas sector, $10 \%$ work in the commercial sector, another $15 \%$ work in retail, and the remaining work in administrative and other sectors [15].

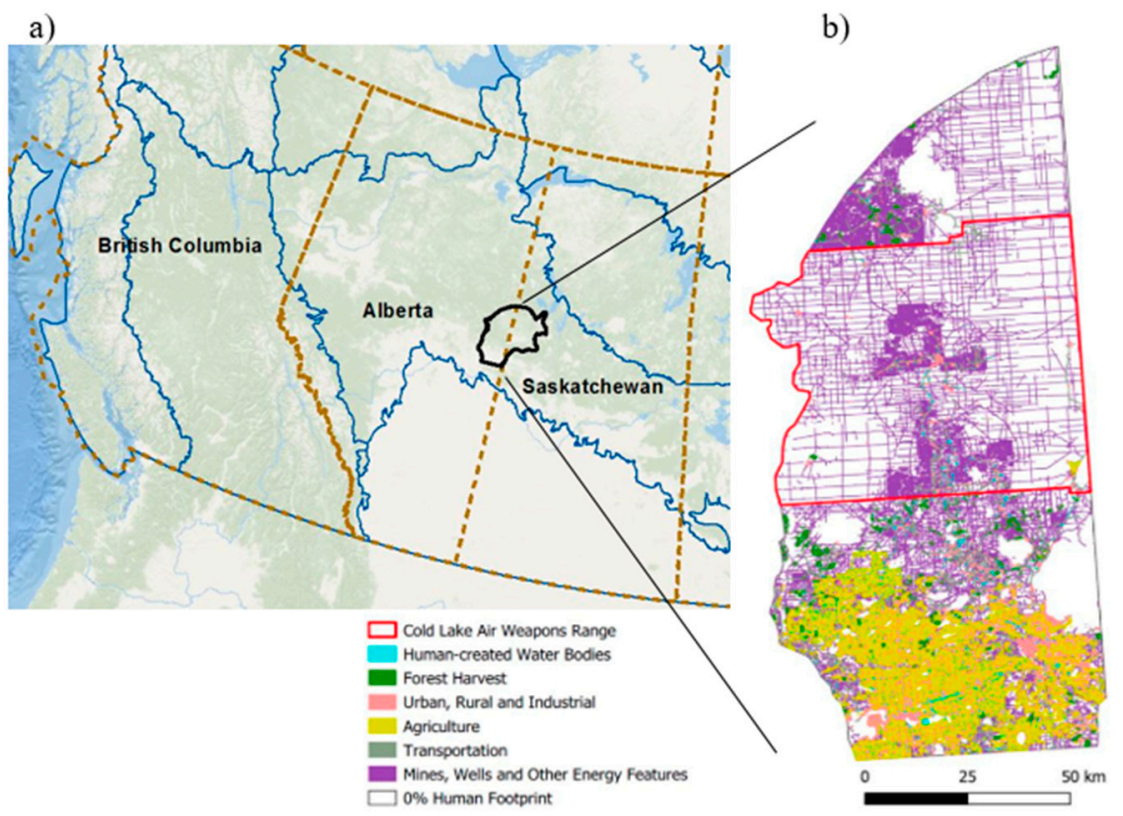

\begin{tabular}{|l|c|c|}
\hline Land Uses Categories & $\begin{array}{c}\text { \% Land Uses In Cold Lake } \\
\left.\text { First Nations Territory } \mathbf{( k m}^{\mathbf{2}}\right)\end{array}$ & $\begin{array}{c}\text { \% Land Uses } \\
\text { in Alberta }\end{array}$ \\
\hline Agriculture & $11.1(1249)$ & 20.3 \\
\hline Energy & $3.2(364)$ & 2.0 \\
\hline Urban, Rural, Industrial & $1.3(144)$ & 1.0 \\
\hline Transportation & $1.2(130)$ & 1.4 \\
\hline Forest Harvest & $0.8(93)$ & 4.4 \\
\hline Human-Created bodies & $0.1(10)$ & 0.2 \\
\hline $\begin{array}{l}\text { Cold Lake Air Weapon } \\
\text { Range }\end{array}$ & $41.7(4700)$ & Does not apply \\
\hline $\begin{array}{l}\text { Total (without Cold Lake Air } \\
\text { Weapon Range }\end{array}$ & $17.7(1990)$ & 29.4 \\
\hline
\end{tabular}

Figure 1. (a) Study area showing the Cold Lake First Nations (CLFN) traditional land within the provinces of Alberta and Saskatchewan in Canada. (b) The human footprint and the percentages of land uses in Cold Lake First Nations territory in the province of Alberta [16].

The Nation maintains the philosophy of "a livelihood for a livelihood," whereby it is understood by its community members that if anyone should achieve a livelihood from CLFN's traditional territory, then so too shall all the members of CLFN. This philosophy has inspired the Nation to maintain a successful economic development portfolio that, in recent decades, has generated significant revenues and employment opportunities for the community. They own and operate over 30 companies, with a 
predominant economic focus on the oil and gas sector in Northern Alberta. In addition to businesses in the industrial sector, the Nation owns a casino, a Courtyard Marriott Hotel, and several service industry establishments in the City of Cold Lake. The community, however, recognizes that there is a need to diversify its economy due to the cyclical nature of the oil and gas economy, which a majority of the Nation's businesses rely on.

\section{Materials and Methods}

To benefit from the wood-based bioenergy, CLFN must have a clear understanding of the local feedstock supplies before entering into project development. In this section, we describe the data used to quantify the local biomass feedstock and to evaluate the potential environmental and socio-economic challenges to access and valorize it. The biomass mobilization approach is based on remote and ground data gathered in collaboration with the community. The socio-economic data were provided by the community. We also investigated the impact of the human footprint and wildland fire in the landscape on the biomass supply. Finally, we looked at GHG emissions that can potentially be offset by the utilization of the different biomass feedstock as a substitute for fossil energy.

\subsection{Human Footprint Data}

A human footprint is defined as visible alterations or conversions of native ecosystems to permanent or temporary agricultural, residential, industrial, and recreational landscapes [16]. The human footprint of an area provides important information that can be mapped out to show where nature has remained relatively intact and where it has been converted into other uses, such as agriculture, transportation roadways, oil and gas development, and urban areas. Biomass mobilization requires an understanding of where raw natural resource materials exist, as well as their physical relation to a human footprint that can help or hinder the utilization of the biomass. For example, an important human footprint in the landscape can be seen as an opportunity because a dense road network can facilitate access to biomass. On the other hand, competition with other natural resource activities, such as oil and gas, can be seen as a barrier to accessing the available biomass. A human footprint also provides useful information for regional land uses planning.

The human footprint data was gathered from the Alberta Biodiversity Monitoring Institute (ABMI) [16]. The ABMI uses human footprint data collected annually from 1999 to 2016 at a 1:5000 scale to track changes in the human footprint over time. Based on ABMI's definition, the main human footprint categories are (1) agriculture, which includes areas of pasture, livestock areas, and confined feeding operations; (2) forestry, which contains forested landscapes that all industrial logging activity occurs in, such as partial-cut, clear-cut, and logging procedures; (3) transportation, which includes all railways, roadways, and trails, with or without hard surfaces and gravel, and vegetation strips beside transportation structures; (4) community or urban/rural area, which includes all residential and commercial buildings, shopping centers, recreation areas, industrial areas, and areas for industrial and commercial development; (5) oil, gas, and other energy sources, which includes areas where soil and vegetation have been disturbed by the establishment of mines, pipelines, transmission lines, well sites, seismic lines, and wind-generating facilities.

\subsection{Compilation of Available Biomass Feedstock}

Multiple sources of woody biomass feedstocks derived from the aboveground biomass (AGB) were assessed in this study. The method of biomass quantification and the type of feedstocks used are similar to those use in [8,9]. The first dataset provides a spatial distribution of the total AGB from tree compartments (stems, bark, branches, and foliage) estimated in oven-dry metric tonne per hectare (odt/ha) in forest stands [17]. The second dataset provides available biomass generated from either harvest residues or fire-killed trees using the spatial distribution of fire and harvest residues in Canada's managed forests [9]. This type of biomass feedstock comes from salvage logging of damaged 
or standing dead trees that remain after natural disturbances, such as diseases, insect outbreaks, and wildfires, that can contribute to bioenergy markets in Canada [18].

\subsection{Fire Data}

This study considered fire risks for two mains reasons. First, the province of Alberta experiences one of the highest risks of wildland fire across Canada [19]. Given that the CLFN is surrounded by forests, the fire risk is high and is, therefore, a liability for the community and for the wood supply chains. Consequently, fire management should be considered in the integrated landscape management for the community. Second, as detailed above, residues from fire-damaged stands could be used as a biomass feedstock. The burned areas and fire risks were estimated using data from the Canadian Wildland Fire Information System data [20] from the last 40 years. The burn rate, defined as the annual average percent of area affected by wildfires, was calculated for the CLFN territory in Alberta and Saskatchewan.

\subsection{Socio-Economic Benefits and Pre-Feasibility Study}

Cold Lake First Nations has considered several options for its wood-based bioenergy plan. One of the sustainable and potential solutions for the community to utilize its biomass resources is to create a wood pellet plant. A pre-feasibility study was developed in collaboration with H\&W Biogenics [21] to evaluate the socioeconomic benefits of a wood pellet plant in the community. The wood pellet plant could enable workers to stay in their community and encourage capital to re-circulate within the community rather than leave, and this retention of capital could contribute to a sense of self-sufficiency. The wood pellet plant could also bolster local and regional economic development. In this pre-feasibility study, the capacity of the pellets was assumed at 20,000 tonnes per year with a wood supply at no cost. The study also ran a scenario that assumed that the facility purchased wood at $\$ 40.00 /$ tonne. The summary of the pre-feasibility study is presented in the results section below.

\subsection{Energy Consumption and GHG Emission Mitigation Potential}

CLFN is not considered a remote indigenous community because the community is connected to the grid and has access to different sources of energy, such as oil and gas, for electricity and heating. These energy sources, however, produce a certain level of GHG emissions that can potentially be offset by the utilization of the different biomass feedstocks described above. At the time of this study, the two types of energy consumed that were available in CLFN were electricity and natural gas for some of the residential and community properties (First Nations Power Authority). In order to assess the annual energy consumption of electricity and available natural gas, the total monthly energy usage for one year was summed for each community building and facilities based on the years 2017 and 2018 and converted into gigajoules (Appendix A). The total annual consumption for electricity and gas was evaluated to be $19,836 \mathrm{GJ}$, with the casino being the most important energy consumer. Note that these values may not represent the full energy consumption of the community but are within the range of provincial estimates. In Alberta, the average household uses $110 \mathrm{GJ}$ of natural gas and $26 \mathrm{GJ}$ of electricity per year for a total of $136 \mathrm{GJ}$ [22].

To calculate the GHG mitigation potential, we used the bioenergy GHG calculator developed by Natural Resources Canada (https://apps-scf-cfs.rncan.gc.ca/calc/en/bioenergy-calculator). Based on the methodology developed by Laganière et al. (2017) [23], this tool made it possible to estimate the potential and timing of GHG emissions reduction when bioenergy from a forest is used as a substitute for fossil energy. The uncertainty in the GHG emissions reduction timing was also provided. The results are presented in 100-year periods and start at year 0 with the production and utilization of bioenergy sourced from a sustainably managed forest. The parameters of the model are defined in Table 1. We built different scenarios by testing two types of feedstocks, namely, harvest residues and fire residues transformed into pellets as a substitute for natural gas, and we also tested two types of energy, namely, heat production and electricity. 
Table 1. Model parameters used in the greenhouse gases mitigation calculator (see [23] for more details).

\begin{tabular}{|c|c|}
\hline Model Parameters & Description \\
\hline Feedstock considered & $\begin{array}{l}\text { Salvaged trees: Salvaged trees are defined as standing trees killed by natural } \\
\text { disturbances. The stemwood is harvested for bioenergy, while the residues } \\
\text { are left on site (i.e., what happens to the residues is not considered in the } \\
\text { calculation). When salvaged trees are not used to produce bioenergy, } \\
\text { the model assumes that they are left on site to decompose. Silvicultural } \\
\text { practices (e.g., site preparation, tree planting, weed control) may increase } \\
\text { forest regeneration and growth following biomass harvesting. } \\
\text { Harvest residues: Harvest residues are defined as all woody debris } \\
\text { generated in harvesting operations for traditional wood products (e.g., } \\
\text { branches, tree tops, bark), excluding stumps and downed non-merchantable } \\
\text { trees. When harvest residues are not used to produce bioenergy, the model } \\
\text { assumes that they are left on site to decompose. }\end{array}$ \\
\hline Mean annual temperature & $1^{\circ} \mathrm{C}$ degrees (estimated at Cold Lake airport) \\
\hline Transformation feedstock & $\begin{array}{l}\text { Wood pellets: A2 grade, moisture } 8 \% \text { wet basis. } \\
\text { Higher heating value }(\mathrm{HHV})=16.5 \mathrm{MJ} / \mathrm{kg}(4.6 \mathrm{kWh} / \mathrm{kg}) \text {. }\end{array}$ \\
\hline Place of use & Local market (no transportation) \\
\hline Energy conversion & Heat or electricity \\
\hline Bioenergy system conversion & $75 \%$ \\
\hline Fossil fuel replaced & Natural gas \\
\hline Fossil fuel system efficiency & $85 \%$ \\
\hline
\end{tabular}

\section{Results}

\subsection{Human Footprint}

As of 2016, the CLFN's total human footprint covered an area of 190,900 ha and represented about $17.7 \%$ of CLFN's land (Figure $1 b$ ). More than $11 \%$ of this land is used for agriculture, making it the dominant land use of the area. Agricultural lands are primarily located in the southern and western portions of the CLFN territory. With 3.2\%, oil and gas is the second most important sector in the landscape. The area is known as the Cold Lake oil sand deposit and is among the three major oil sand deposits in Alberta, along with the Peace River and Athabasca deposits [24].

Transportation and urban features make up $2.5 \%$ of the landscape and represent the third most important land use. Although forestry is the largest land use within Alberta's boreal forest, it is not the largest land use within CLFN. With $0.8 \%$ of the area, timber extraction does occur directly east and north of CLFN land (Figure 1b).

Not counted as a human footprint per se, but of critical importance for the CLFN land use and access is the Cold Lake Air Weapons Range (CLAWR) operated by the Royal Canadian Air Force (Figure 1b). Established in 1952 during the Cold War era and covering about 470,000 ha in the province of Alberta, the military base has prevented CLFN members from accessing large portions of their traditional lands and made it challenging to logistically gain access to the northern regions. Indeed, with more than $41 \%$ of the CLFN land, CLAWR is the most extensive footprint in the CLFN land. Although some portions of the CLAWR territory have granted access to oil and gas activities, the right to use this area for CLFN members is still challenged and contested for traditional usages, such as fishing, hunting, and lodging.

\subsection{Biomass Available}

Aboveground biomass within CLFN is estimated at $46 \pm 57$ odt/ha (Figure 2), and theoretically, harvest residues are estimated at $18 \mathrm{odt} /$ ha (Figure 3a). Fire residues are estimated at $78 \mathrm{odt} / \mathrm{ha}$; however, note that a $50 \%$ net-down factor needs to be applied to account for ecological 
biomass retention on sites (Figure 3). In order to comply with sustainable forest management criteria in Canada, biomass harvesting from naturally disturbed stands are assessed based on their theoretical potential, which is the maximum potential that biomass can be mobilized from a sustainably managed forest [25], but the amount of available biomass for cost-benefit analysis is generally reduced by between 30 and $50 \%$ to take into account sustainability concerns and recovery rates $[8,9,26]$. Therefore, the fire residues biomass is estimated at 39 odt/ha within CLFN land after a 50\% net-down. In comparison, ref. [26] estimated the biomass from fire residues at $49 \mathrm{odt} / \mathrm{ha} /$ year after a $50 \%$ net-down in the boreal plain ecozone. This lower estimate can be explained because CLFN is located in the southern less productive stands and the region seems to be protected from the high risk of fire, despite its close proximity with fire hotspots (Figure 3).

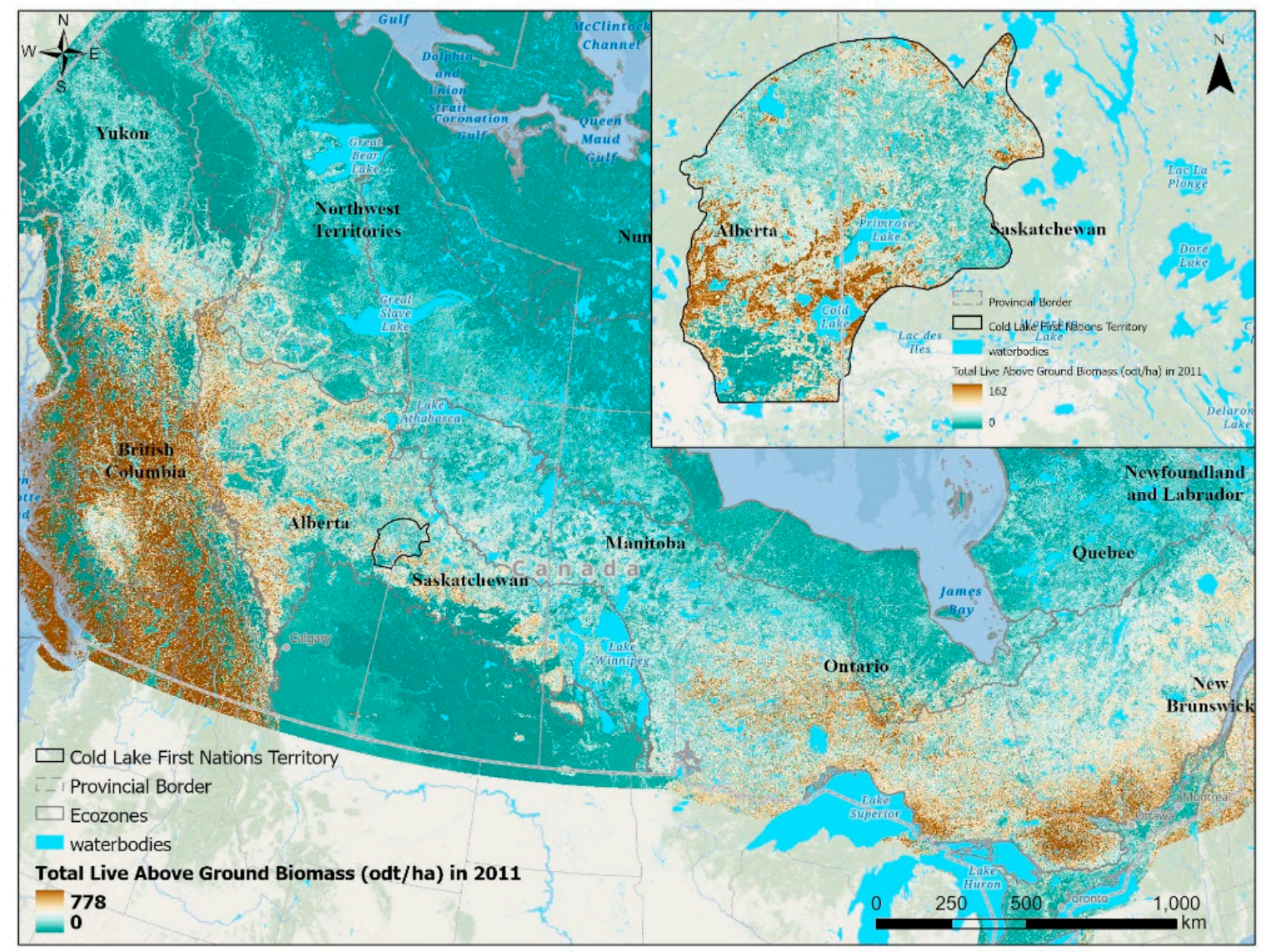

Figure 2. Density of the aboveground biomass (oven-dry metric tonne odt/ha). 


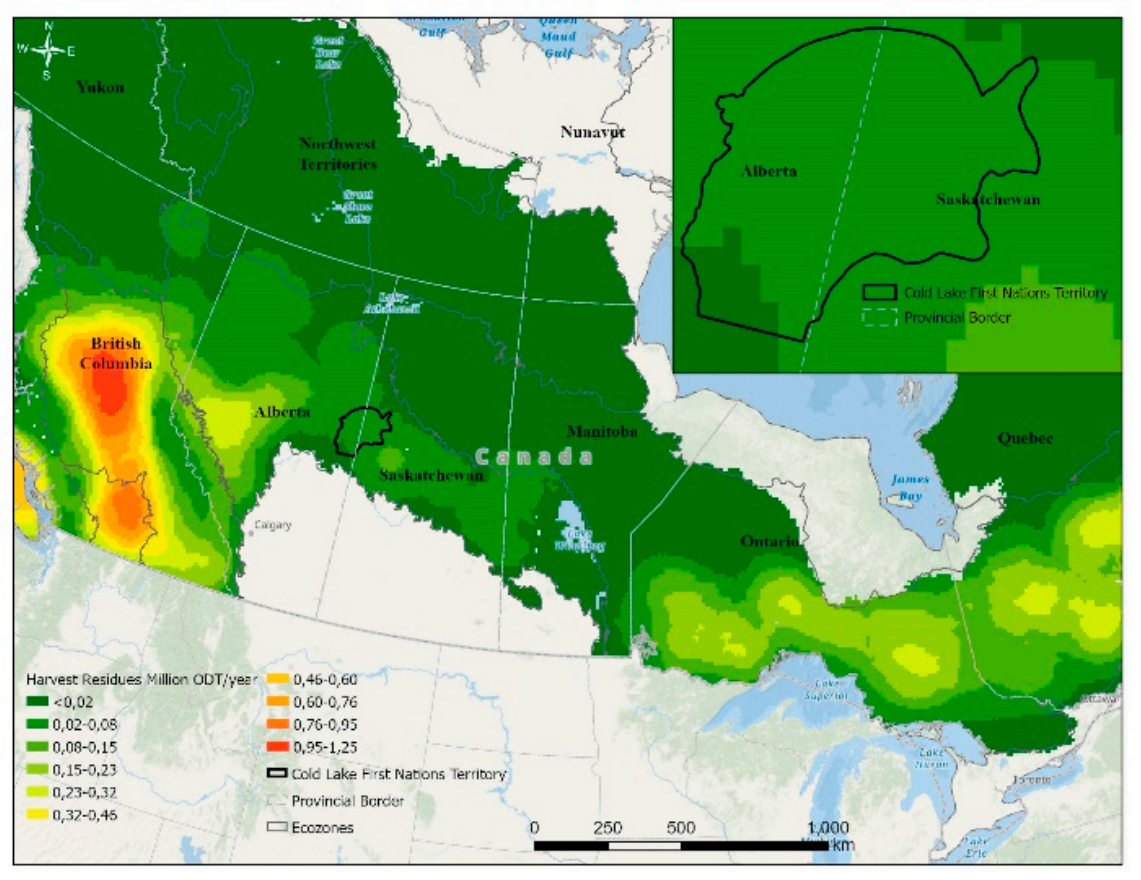

(a)

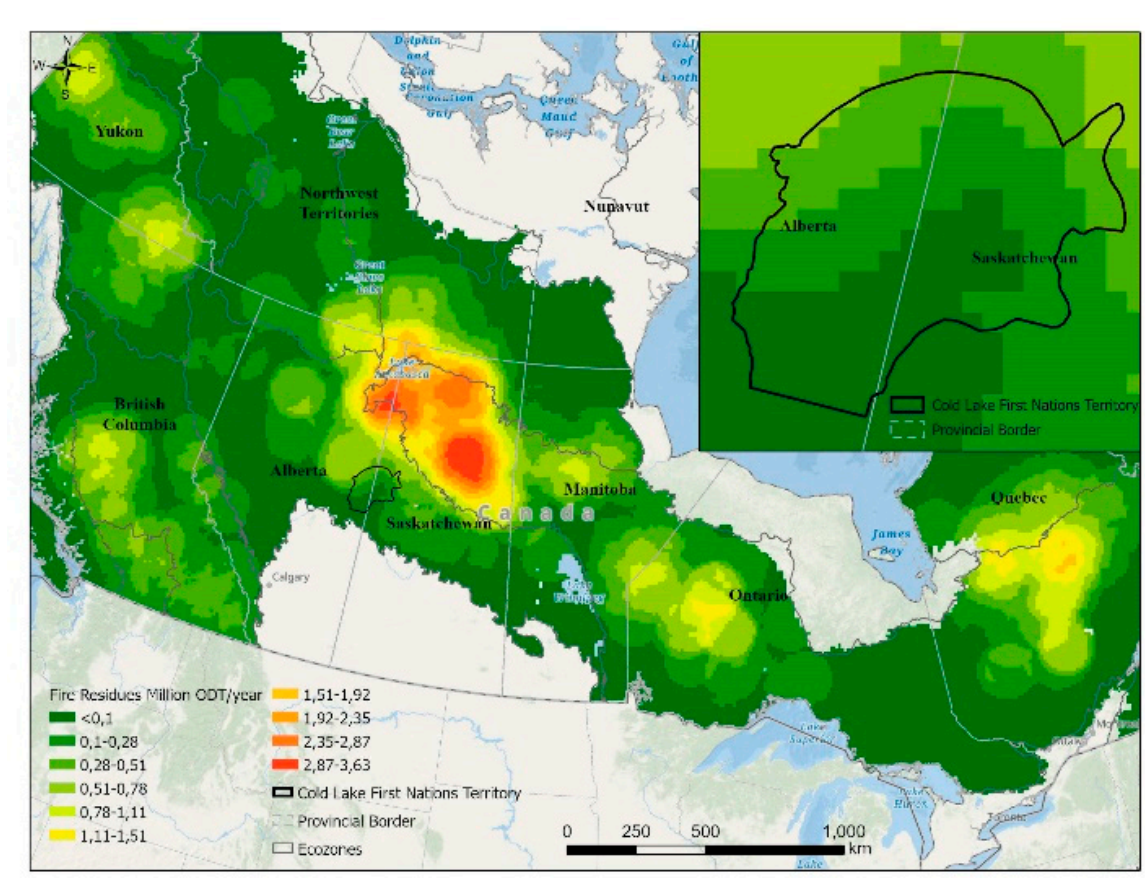

(b)

Figure 3. Estimates of the theoretical biomass availability in millions oven-dry tonnes per year from (a) harvest residues and (b) fire residues (modified from [9]). 
Given its location in the oil patch, CLFN are in a unique situation because they receive woody biomass from local oil and gas producers that operate in CLFN's traditional territory that is estimated to be $19,000 \mathrm{odt} /$ year (assuming a moisture content on a wet basis of $50 \%$ ). The amount of wood supply from the oil and gas industry has been estimated at 50,000 $\mathrm{m}^{3}$ of spruce, pine, and poplar per year [21]. In addition, about 21,320 tonnes of round wood was stored on project sites. Part of the agreement between CLFN and the local oil and gas companies is that CLFN would receive free wood biomass delivered to the community sawmill each year. Although the sawmill located in the CLFN is currently not working for safety reasons, and therefore cannot process the wood, this biomass delivered for free represents an opportunity to investigate wood-based energy facilities as it is located in the center of the community and is in close proximity to important transport networks. However, because the wood is accumulating on the sawmill site, the community was also concerned about the potential fire risks.

Considering that agriculture represents the most expensive land use in the area, it is relevant to mention that crop residues can also represent a substantial volume of feedstock for bioenergy. Agricultural residues are the cheapest and most accessible feedstock for bioenergy in Canada [27], and unlike forest residues, they do not require harvest restrictions for sustainability purposes. Considering that the major crops grown in the country, including cereals, oilseeds, and pulses, can provide up to $80 \mathrm{million}$ odt/year of agricultural residues, large quantities of these agricultural feedstocks could be available every year across Canada for the bioenergy sector [28].

\subsection{Fire History}

Fire history maps show that, cumulatively, nearly 1 million ha of the CLFN territory has burned since 1980 within both the Alberta (237,000 ha) and Saskatchewan sides (730,000 ha; Figure 4). The largest fires happened in 1980, 1993, 1995, and most recently in 2015, with burned areas of $341,387 \mathrm{ha}, 317,615 \mathrm{ha}, 87,120 \mathrm{ha}$, and 130,486 ha, respectively. The average of the burned area since 1980 is 25,487 ha per year, with 12,500 ha in Alberta and 38,000 ha in Saskatchewan (Figure 4). Most of the largest fires (approximately 75\%) happened on the Saskatchewan side. This number highlights a major difference in the fire risk between the two regions. Although Saskatchewan has a larger total burned area for this region, it also has significantly less oil and gas development compared to the Alberta side in this region. With a large amount of costly infrastructure to protect and more risk of loss, we assumed that the difference between the two provinces can be explained by a more intensive and effective fire suppression on the Alberta side.

While intensive fire suppression suggests that there are less fire residues available for harvest, the impact of climate change also needs to be considered to evaluate this feedstock in the future. Under future climate scenarios, many studies have anticipated an increase in fire risk, with potential changes in the biomass available [19,29]. For example, the merchantable volume at risk of fire in Alberta is expected to increase by $40 \%$ in the 2071-2100 period [29]. Indeed, the increasing volume at risk of natural disturbances, such as fire or drought, in some areas of the commercial forest (potentially reaching nearly $100 \%$ of the total volume) suggests that it may be challenging to maintain the current harvest rate without enacting measures that attenuate the negative impacts on the forest sector [18]. Wood-based bioenergy systems supplied by harvest and fire residues need to account for this variation and uncertainty in the volume available from year to year because a stable biomass supply chain is key to an efficient and cost-effective bioenergy system [14]. 

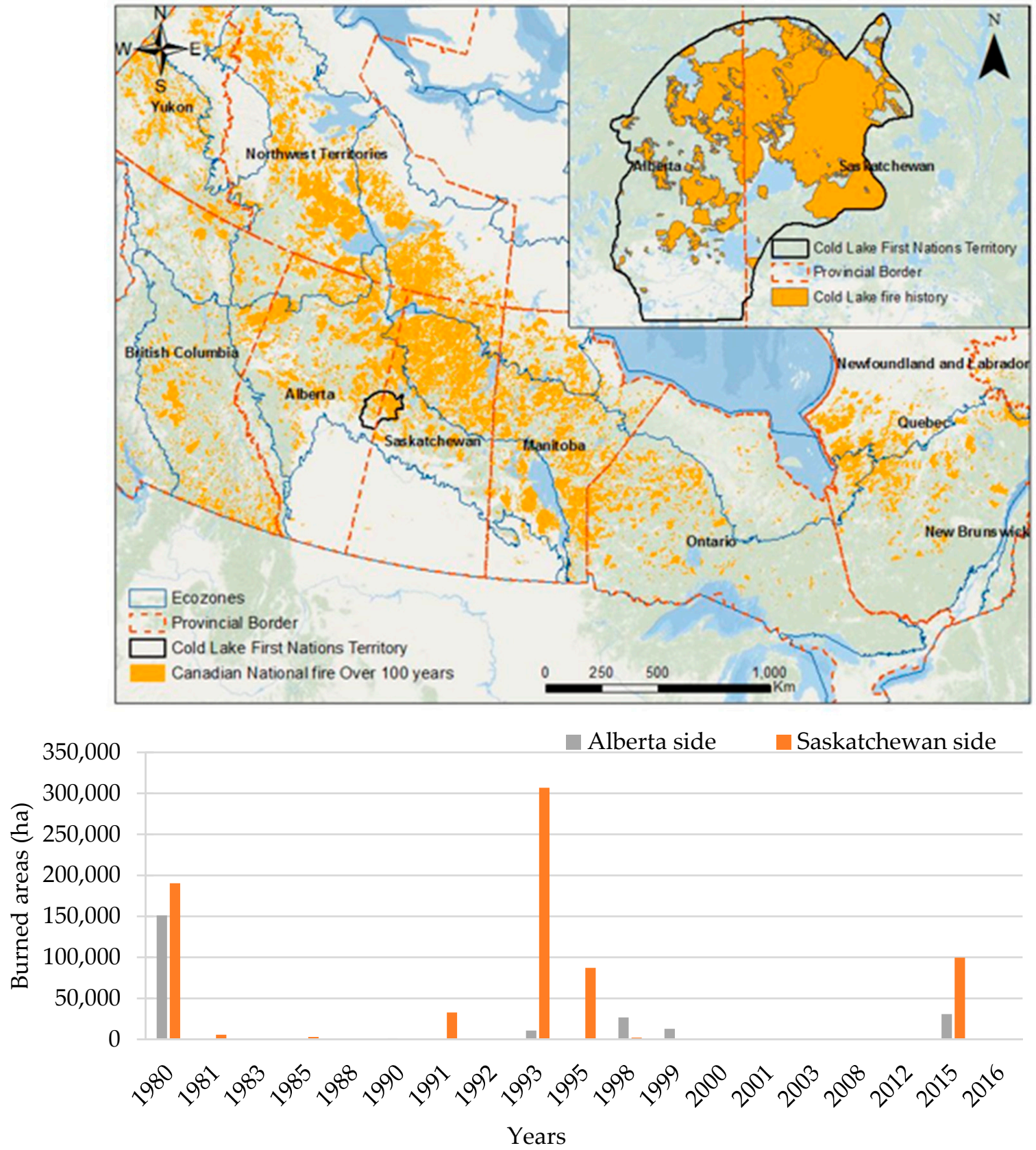

Figure 4. Burned areas and fire history in CLFN in the provinces of Alberta and Saskatchewan.

\subsection{Socio-Economic Assessment}

According to a pre-feasibility study by [21], a small wood pellet plant with a capacity of 20,000 tonnes/year may be profitable for the CLFN community (see Appendix B for a summary of the revenues and expenditures of the wood pellet plant). The study covered 10 years and provided a worst-case scenario of a $100 \%$ financing requirement for the wood pellet plant and assumed no other funding or other incentives are available. The scenario also assumed that the bulk price for pellets would increase and that the plant would operate at near full capacity by utilizing the salvaged wood from the oil and gas sector, which would be provided free of charge with consistent and guaranteed volumes. According to the study, under the abovementioned assumptions, over 10 years, a wood pellet plant would bring in $\$ 36.3$ million in revenue with $\$ 21.5$ million in operating and capital costs, resulting in gross revenue of $\$ 14.8$ million. The costs include a facility capital cost of $\$ 3.8$ million, resulting in debt payments over 10 years of $\$ 4.7$ million, operations and maintenance of $\$ 9$ million, 
and human resources of $\$ 7.7$ million. The payback period for the facility was approximately 3 years, which is a relatively short time. The revenues include operating revenues based on output tonne and federal government revenues from carbon offsets. In the worst-case scenario, the pre-feasibility study showed that the pellet plant is indeed feasible. Note, however, that the largest risk for this type of project is the sustainability and dependability of the salvaged wood supply from the oil and gas sector at no cost. The study also ran a scenario that assumed that the facility purchased wood at $\$ 40.00 /$ tonne, and the estimates still showed that the project was still viable. A challenge, however, may be that logistically, smaller-scale wood pellet mills typically require coordination with a local sawmill to utilize the waste products as a feedstock; given that CLFN does not currently have an active sawmill, future synergies may be limited, even if they are economically viable.

\subsection{GHG Emissions Mitigation from Bioenergy}

The results of the different scenarios showed that only bioenergy sourced from harvest residues that replace natural gas for producing heat can result in GHG mitigation potential after 25 years in the best scenario or 45 years in the worst scenario (Figure 5). Fire residues or harvest residues used to produce electricity as a means to replace natural gas cannot mitigate GHG emissions in any of the scenarios or time frames considered. These results are consistent with other similar studies. Most studies document a carbon parity time of $<20$ years for bioenergy that is sourced from harvest residues, excluding stumps [22,30,31]. Harvest residues offer more GHG benefits than salvaged trees because in our scenario, when harvest residue is not used to produce bioenergy, the model assumed that the residue is left on site to decompose, while the harvest of biomass from salvaged trees require additional forest operations that can reduce the GHG benefits.

Table 2. Estimation of the biomass available from local oil and gas producers for different types of feedstock in CLFN's traditional territory. * This estimation is highly variable and depends on the operations in the oil and gas sector in the area [21].

\begin{tabular}{lccc}
\hline Types of Feedstock & Harvest Residues & Fire Residues & $\begin{array}{c}\text { Forestry Residues from } \\
\text { Oil and Gas Activities * }\end{array}$ \\
\hline Amount of Residue & $18 \mathrm{odt} / \mathrm{ha}$ & $39 \mathrm{odt} / \mathrm{ha}$ & $19,000 \mathrm{odt} / \mathrm{year}$ \\
\hline
\end{tabular}




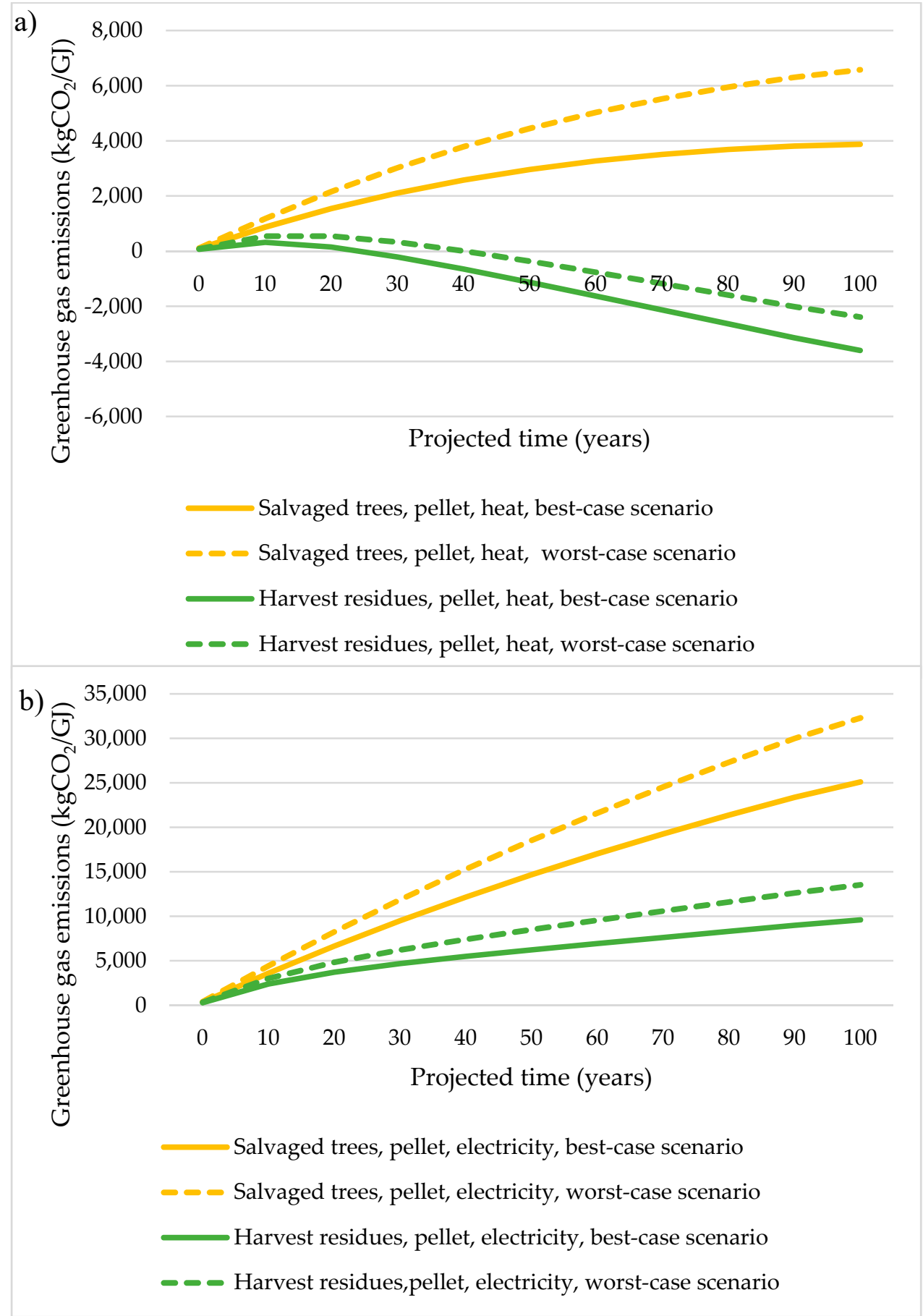

Figure 5. Greenhouse gas mitigation potential according to different scenarios involving replacing natural gas (a) to produce heat and (b) to produce electricity (in a 100-year time frame), starting in year 0 with the use and production of bioenergy sourced from a forested landscape that is managed sustainably. Positive values represent carbon emission, while negative values represent carbon sequestration. The time to carbon sequestration parity is defined as the time between when the biomass was harvested and when the overall carbon offsets the loss of the carbon that normally would be stored if the biomass had not been harvested. The difference between the best and the worst-case scenario is the range between the shortest and the longest carbon parity time (see [23] for more details). The scenario parameters are defined in Table 2. 


\section{Discussion}

\subsection{Challenges of Biomass Mobilization under Overlapping Land Uses}

In Canada, boreal forests have been recognized as a stable and long-term biomass supply, which could be used for bioenergy [32]. This study confirmed that there is a large and various amount of biomass available for bioenergy from harvesting residues and natural disturbances, such as fire (Table 2). Meanwhile, given that CLFN is located in the southern portion of the Boreal Plain ecozone at the border with the aspen rangeland, the density of biomass is lower than the other forested regions in Alberta. In comparison, the largest density of biomass in the province is found in the western Foothills and the Rocky Mountains ecoregions with 90 and 120 odt/ha, respectively [33]. The harvest residues estimated in this study were also at the lower end of the national estimates in Canada. In comparison, the most productive forest can provide around $30 \mathrm{odt} /$ ha of harvest residues in coastal British Columbia and southern Ontario [34]. The availability of harvest residues is directly influenced by the level of logging, which is relatively insignificant in the Cold Lake area, as mentioned above. The CLFN is also in a unique position because the community benefits from a free biomass supply from the oil and gas industries operating on their land.

Despite the multiple biomass feedstocks available to the CLFN community, our results confirmed that potential barriers may exist in developing sustainable and competitive biomass supply chains in Indigenous communities [35]. In this study, the biomass resources seem particularly spatially constrained given the cumulative effects of the human footprint and burned areas in the landscape. The human footprint in the CLFN region has a significant amount of oil and gas infrastructure, combined with road, railway, and pipeline networks, which can make the biomass more difficult to access (Figure 1b). All of these human footprints, combined with the Cold Lake Air Weapon Range, which constrains the access of $40 \%$ of their land, make it difficult for CLFN to access the vast forest resources available in the region.

Potential barriers in developing wood-based bioenergy in northern Indigenous communities have been reported in the literature [10,11]. In particular, the lack of ownership or management of natural resources by and for the communities have been documented, thus reducing their capacity and leadership to lead bioenergy projects. In this study, given the limited access to their land, the community, therefore, remains highly dependent on the biomass delivered by the oil and gas industries as the only feedstock available for bioenergy. However, the volume of that biomass alone has been proven to be insufficient and unstable to consistently supply a potential pellet facility in a cost-efficient manner [21]. Additionally, the cumulative effects of environmental and anthropogenic factors on the landscape need to be considered when assessing biomass procurement. The community may be in conflict with bioenergy development due to the size of their footprint, or negative impacts on the environment [35]. In the case of CLFN, the landscape is extensively fragmented by the network of pipelines and well pads, with considerable impacts on the ecosystem and biodiversity, especially the woodland caribou, which is an endangered species in the region [36]. Salvage logging has been documented to impact negatively on forest sites, biodiversity, and other ecosystem services [37]. Implementing salvage logging practices for biomass procurement in the area will require trade-offs and optimized land-use management to avoid additional disturbances in the landscape [38].

\subsection{Socio-Economic and Environmental Challenges}

Given the location of the community within one of the most productive oil and gas regions in the world, challenges exist for CLFN to utilize its biomass as an energy source. Inexpensive oil and natural gas may make it difficult for wood pellets based on bioenergy to compete. For example, a market may exist for wood pellets, or (if deemed feasible) a heating district; however, the price of substitute energy sources will impact the competitiveness of the wood biomass. For example, the creation of a combined heat and power (CHP) system to utilize the salvaged wood provided by the oil and gas industry would not be economically feasible without significant subsidies. A CHP system would 
produce approximately $\$ 0.10$ to $\$ 0.18$ per $\mathrm{kWh}$ or even higher for smaller applications, which is significantly higher than what the CLFN currently pays for electricity ( $\$ 0.0765$ per $\mathrm{kWh}$ ), making the project unviable [21]. Moreover, because the biomass is supplied by the oil and gas industry directly at the site of the existing sawmill, there is no local job creation related to the harvesting and transportation of biomass for this scenario.

Indigenous communities face environmental and economic challenges in managing their own resources. This study confirmed that replacing natural gas with wood-based bioenergy offers less GHG benefits than replacing coal or oil, as shown in [23]. In our case, using pellets to produce heat or electricity for the local community will generate more GHG emissions than using natural gas, except in the case of harvest residues. While a wood-based bioenergy system can provide a major opportunity to address climate change by reducing fossil $\mathrm{CO}_{2}$ emissions [39], this study suggests that a bioenergy system needs to be carefully planned to ensure sustainability and efficient GHG mitigation. Sustainable and competitive biomass supply chains can be implemented by restoring community-based management. Many examples of community-based forestry have demonstrated the success of designing, developing, and commercializing non-timber and timber forest products based on indigenous knowledge and management [40-42]. Community-based resource management also has the benefit of transferring the responsibility and leadership to the local community and reducing their dependence on external resources and skilled workforces. Additionally, community management that utilizes local labor and consultants can mitigate the cost of forest operations, educate and train community members, and revitalize the community $[43,44]$. In the context of intensive natural resource extraction, many studies have highlighted the role of local and community-based monitoring to maintain and restore ecosystem functions and services [45]. Although biomass quantification and a stable biomass supply chain are crucial for any wood-based bioenergy project, there is much to be done in the human and social dimensions to create a more integrated and complementary view of biomass management for bioenergy.

\section{Conclusions}

Cold Lake First Nations, which has significant forest resources, can potentially grow the local bioeconomy through new utilizations of its biomass resources. The community is in a unique situation whereby they receive free woody biomass from local oil and gas producers that operate in CLFN's traditional territory, in addition to harvest and fire residues available on their land. However, socio-economic and environmental barriers remain. Though abundant, the woody biomass is difficult to access due to the human footprint that surrounds the area and constrains the landscape. In terms of cost savings, the low oil and gas prices make the production of heat via biomass resources (pellets) less competitive to utilize than the natural gas available in the community. In terms of GHG mitigation, the potential also appears limited because the community has access to natural gas at a competitive and stable price, unlike off-grid communities.

This study demonstrates that despite having abundant biomass resources, bioenergy projects can be complex. Every bioenergy project must be developed with careful consideration of the regional and local socio-economic factors that affect the biomass supply chain. While bioenergy development can support a diverse, low-carbon economy, it is imperative to ensure that Indigenous-led bioenergy projects promote their self-reliance to develop a sustainable supply chain that is integrated with values and community priorities.

Author Contributions: Conceptualization, N.M.; methodology, N.M.; software, L.T.; validation, N.M., L.T. and D.S.; data curation, L.T.; writing—original draft preparation, N.M. and D.S.; writing—review and editing, N.M. and D.S.; supervision, N.M.; project administration, N.M.; funding acquisition, N.M. All authors have read and agreed to the published version of the manuscript.

Funding: This research was funded by the Canadian Forest Service Forest Innovation Program.

Acknowledgments: Our sincere thanks to Fin MacDermid and Kyle Martin of Cold Lake First Nations for providing data and useful comments on the manuscript. 
Conflicts of Interest: The authors declare no conflict of interest.

\section{Appendix A}

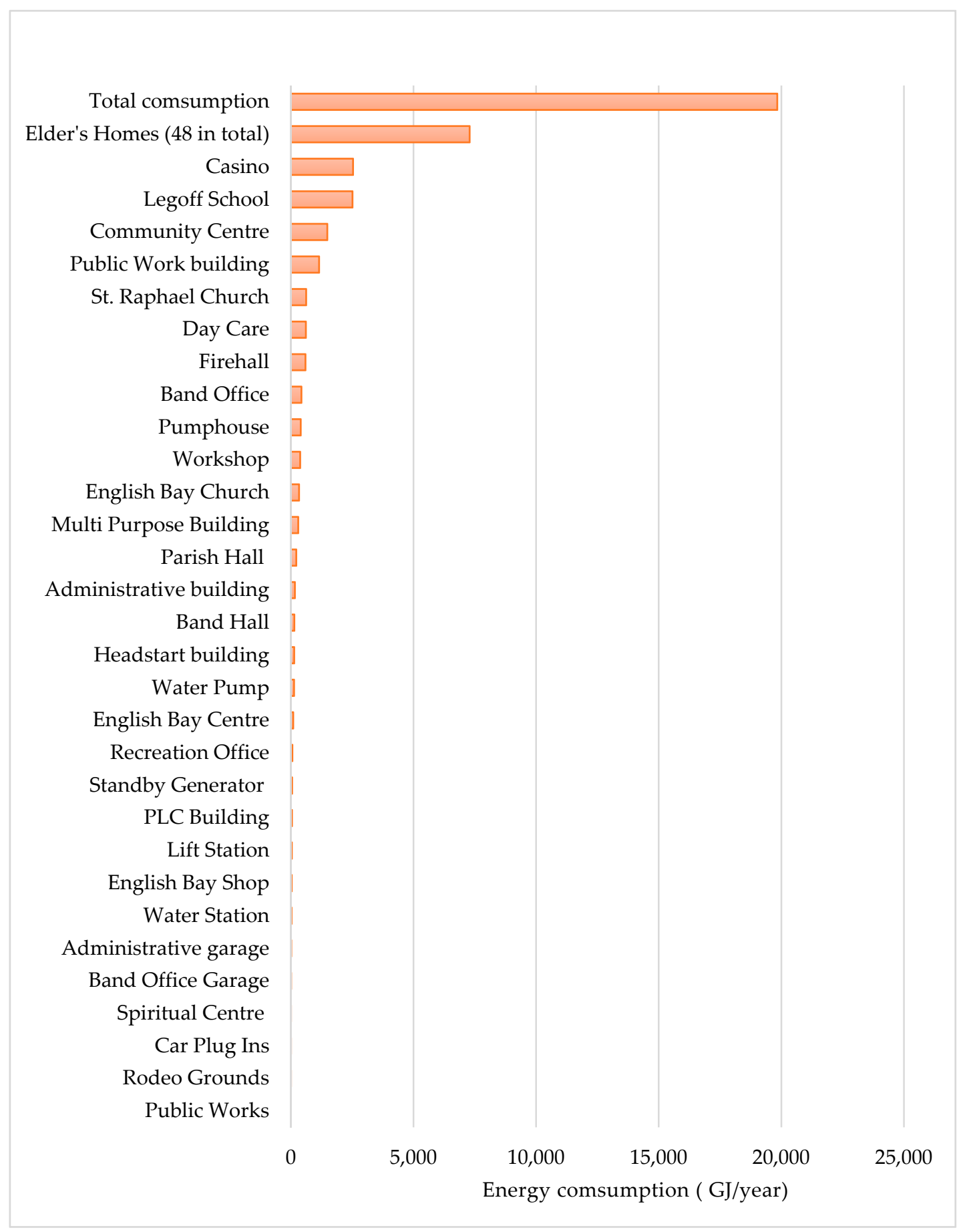

Figure A1. Energy usage (based on electricity and natural gas consumption) of community buildings and facilities, based on 2017 and 2018 (Source: Cold Lake First Nations). 


\section{Appendix B}

\begin{tabular}{|c|c|c|c|c|}
\hline & \multicolumn{2}{|c|}{ Scenario \#1 } & \multicolumn{2}{|c|}{ Scenario \#2 } \\
\hline Wood Pellet Plant $(20,000$ tonnes/year) & \multicolumn{2}{|c|}{$70 \%$ Financing } & \multicolumn{2}{|c|}{$100 \%$ Financing } \\
\hline Project Capital Cost & $\$$ & $2,596,650$ & $\$$ & $3,885,000$ \\
\hline \multicolumn{5}{|l|}{ Expenses: } \\
\hline Project Capital Costs with Debt Payments (10-yrs) & $\$$ & $3,303,960$ & $\$$ & $4,719,960$ \\
\hline Operations \& Maintenance (10-yrs) & $\$$ & $9,047,962$ & $\$$ & $9,047,962$ \\
\hline Human Resources (10-yrs) & $\$$ & $7,726,766$ & $\$$ & $7,726,766$ \\
\hline \multicolumn{5}{|l|}{ Revenues: } \\
\hline Revenues from operations (10-yrs) & $\$$ & $36,334,985$ & $\$$ & $36,334,985$ \\
\hline Gross Revenues (over 10-year period) & $\$$ & $16,256,297$ & $\$$ & $14,840,297$ \\
\hline
\end{tabular}

Figure A2. Summary of expenditures and revenues for the installation of a pellet plant in Cold Lake First Nations based on [21].

\section{References}

1. United Nations Development Programme (UNDP). Handbook for Conducting Technology Needs Assessment for Climate Change, New York. 2014. Available online: https://unfccc.int/sites/default/files/ 1529e639caec4b53a4945ce009921053.pdf (accessed on 4 April 2020).

2. A Forest Bioeconomy Framework for Canada; Canadian Council of Forest Ministers: Ottawa, ON, Canada, 2017; 30p.

3. Pan Canadian Framework on Clean Growth and Climate Change. Canada's Plan to Address Climate Change and Grow the Economy; Catalogue no. En4-294/2016E-PDF; Government of Canada: Ottawa, ON, Canada, 2016.

4. Statistics Canada. Canada. Aboriginal Population Profile, 2016 Census. Statistics Canada Catalogue no. 98-510-X2016001. Ottawa. Released July 18, 2018. Available online: http://www12.statcan.gc.ca/censusrecensement/2016/dp-pd/abpopprof/index.cfm?Lang=E (accessed on 6 January 2020).

5. Zurba, M.; Stucker, D.; Mwaura, G.; Burlando, C.; Rastogi, A.; Dhyani, S.; Koss, R. Intergenerational Dialogue, Collaboration, Learning, and Decision-Making in Global Environmental Governance: The Case of the IUCN Intergenerational Partnership for Sustainability. Sustainability 2020, 12, 498. [CrossRef]

6. Natural Resources Canada. Clean Energy for Rural and Remote Communities: BioHeat, Demonstration \& Deployment Program Stream. 2018. Available online: https://www.nrcan.gc.ca/reducingdiesel (accessed on 6 August 2020).

7. Coote, D.C.; Thiffault, E.; Brown, M. Constraints and Success Factors for Woody Biomass Energy Systems in Two Countries with Minimal Bioenergy Sectors. In Mobilisation of Forest Bioenergy in the Boreal and Temperate Biomes; Thiffault, E., Smith, C.T., Junginger, M., Berndes, G., Eds.; Academic Press: Cambridge, MA, USA, 2016; pp. 165-189.

8. Mansuy, N.; Thiffault, E.; Lemieux, S.; Manka, F.; Paré, D.; Lebel, L. Sustainable biomass supply chains from salvage logging of fire-killed stands: A case study for wood pellet production in eastern Canada. Appl. Energy 2015, 154, 62-73. [CrossRef]

9. Mansuy, N.; Paré, D.; Thiffault, E.; Bernier, P.Y.; Cyr, G.; Manka, F.; Lafleur, B.; Guindon, L. Estimating the spatial distribution and locating hotspots of forest biomass from harvest residues and fire-damaged stands in Canada's managed forests. Biomass Bioenergy 2017, 97, 90-99. [CrossRef]

10. Bullock, R.C.; Zurba, M.; Parkins, J.R.; Skudra, M. Open for bioenergy business? Perspectives from Indigenous business leaders on biomass development potential in Canada. Energy Res. Soc. Sci. 2020, 64, 101446. [CrossRef]

11. Zurba, M.; Bullock, R. Framing indigenous bioenergy partnerships. Int. Indig. Policy J. 2018, 9. [CrossRef]

12. Henderson, C.; Sanders, C. Powering Reconciliation: A Survey of Indigenous Participation in Canada's Growing Clean Energy Economy; Lumos Clean Energy Advisors: Ottawa, ON, Canada, 2017. 
13. Stefanelli, R.D.; Walker, C.; Kornelsen, D.; Lewis, D.; Martin, D.H.; Masuda, J.; Castleden, H. Renewable energy and energy autonomy: How Indigenous peoples in Canada are shaping an energy future. Environ. Rev. 2019, 27, 95-105. [CrossRef]

14. The Ecological Framework of Canada. 2020. Available online: http://ecozones.ca/english/ (accessed on 7 March 2019).

15. Cold Lake First Nations Lands and Resources Department. Available online: https://clfns.com/ (accessed on 10 November 2020).

16. Alberta Biodiversity Monitoring Institute (ABMI). Status of Human Footprint in Alberta. 2019. Available online: https://abmi.ca/home/reports/2018/human-footprint?\#categories (accessed on 1 June 2020).

17. Beaudoin, A.; Bernier, P.Y.; Guindon, L.; Villemaire, P.; Guo, X.J.; Stinson, G.; Bergeron, T.; Magnussen, S.; Hall, R.J. Mapping attributes of Canada's forests at moderate resolution through $\mathrm{k}$ NN and MODIS imagery. Can. J. For. Res. 2014, 44, 521-532. [CrossRef]

18. Edenhofer, O.; Pichs-Madrga, R.; Sokona, Y.; Seyboth, K. Summary for policymakers. In IPCC Special Report on Renewable Energy Sources and Climate Change Mitigation; Cambridge University Press: Cambridge, UK; New York, NY, USA, 2011; pp. 1-24.

19. Boulanger, Y.; Taylor, A.R.; Price, D.T.; Cyr, D.; McGarrigle, E.; Rammer, W.; Ste-Marie, G.; Beaudoin, A.; Guindon, L.; Mansuy, N. Climate change impacts on forest landscapes along the Canadian southern boreal forest transition zone. Landsc. Ecol. 2016, 32, 1415-1431. [CrossRef]

20. Natural Resources Canada. Canadian Wildland Fire Information System (CWFIS). 2019. Available online: https://cwfis.cfs.nrcan.gc.ca/home (accessed on 1 August 2019).

21. H\&W Biogenics Ltd. The Installation of a Wood Pellet Plant and a Wood Fiber Energy System at Cold Lake First Nations. A Prefeasibility Technical Evaluation; H\&W Biogenics Ltd.: Edmonton, AB, Canada, 2019.

22. Statistics Canada. Household Energy Use, by Fuel Type and by Province, 2007-Average Energy Use. 2007. Available online: https://www150.statcan.gc.ca/n1/pub/11-526-s/2010001/t004-eng.htm (accessed on 3 October 2019).

23. Laganière, J.; Paré, D.; Thiffault, E.; Bernier, P.Y. Range and uncertainties in estimating delays in greenhouse gas mitigation potential of forest bioenergy sourced from Canadian forests. GCB Bioenergy 2017, 9, 358-369. [CrossRef]

24. Atkinson, N. Landscapes of the Alberta Oil Sands. In Landscapes and Landforms of Western Canada; Springer: Cham, Switzerland, 2017; pp. 395-410.

25. Smeets, E.M.; Faaij, A.P.; Lewandowski, I.M.; Turkenburg, W.C. A bottom-up assessment and review of global bio-energy potentials to 2050. Prog. Energy Combust. Sci. 2007, 33, 56-106. [CrossRef]

26. Dymond, C.C.; Titus, B.D.; Stinson, G.; Kurz, W.A. Future quantities and spatial distribution of harvesting residue and dead wood from natural disturbances in Canada. For. Ecol. Manag. 2010, 260, 181-192. [CrossRef]

27. Yemshanov, D.; McKenney, D.W.; Hope, E.; Lempriere, T. Renewable energy from forest residues-How greenhouse gas emission offsets can make fossil fuel substitution more attractive. Forests 2018, 9, 79. [CrossRef]

28. Li, X.; Mupondwa, E.; Panigrahi, S.; Tabil, L.; Sokhansanj, S.; Stumborg, M. A review of agricultural crop residue supply in Canada for cellulosic ethanol production. Renew. Sustain. Energy Rev. 2012, 16, $2954-2965$. [CrossRef]

29. Boucher, B.; Boulanger, Y.; Aubin, I.; Bernier, P.; Beaudoin, A.; Guindon, L.; Gauthier, S. Current and projected cumulative impacts of fire, drought, and insects on timber volumes across Canada. Ecol. Appl. 2018, 28, 1245-1259. [CrossRef]

30. Lamers, P.; Junginger, M. The 'debt' is in the detail: A synthesis of recent temporal forest carbon analyses on woody biomass for energy. Biofuels Bioprod. Biorefin. 2013, 7, 373-385. [CrossRef]

31. Lamers, P.; Junginger, M.; Dymond, C.C.; Faaij, A. Damaged forests provide an opportunity to mitigate climate change. Glob. Chang. Biol. Bioenergy 2014, 6, 44-60. [CrossRef]

32. Paré, D.; Bernier, P.; Thiffault, E.; Titus, B. The potential of forestry biomass as a source of energy for Canada. For. Chron. 2011, 87, 345-350. [CrossRef]

33. Zhang, J.; Huang, S.; Hogg, E.H.; Lieffers, V.; Qin, Y.; He, F. Estimating spatial variation in Alberta forest biomass from a combination of forest inventory and remote sensing data. Biogeosciences 2014, 11, 2793. [CrossRef] 
34. Barrette, J.; Paré, D.; Manka, F.; Guindon, L.; Bernier, P.; Titus, B. Forecasting the Spatial Distribution of Logging Residues Across the Canadian Managed Forest. Can. J. For. Res. 2018, 48, 1470-1481. [CrossRef]

35. Krupa, J. Identifying barriers to Aboriginal renewable energy development in Canada. Energy Policy 2012, 42, 710-714. [CrossRef]

36. Hervieux, D.; Hebblewhite, M.; Stepnisky, D.; Bacon, M.; Boutin, S. Managing wolves (Canis lupus) to recover threatened woodland caribou (Rangifer tarandus caribou) in Alberta. Can. J. Zool. 2014, 92. [CrossRef]

37. Thorn, S.; Bässler, C.; Brandl, R.; Burton, P.J.; Cahall, R.; Campbell, J.L.; Castro, J.; Choi, C.Y.; Cobb, T.; Donato, D.C.; et al. Impacts of salvage logging on biodiversity: A meta-analysis. J. Appl. Ecol. 2018, 55, 279-289. [CrossRef] [PubMed]

38. Yemshanov, D.; Haight, R.G.; Liu, N.; Parisien, M.A.; Barber, Q.; Koch, F.H.; Burton, C.; Mansuy, N.; Campioni, F.; Choudhury, S. Assessing the trade-offs between timber supply and wildlife protection goals in boreal landscapes. Can. J. For. Res. 2019, 50, 243-258. [CrossRef]

39. Mansuy, N.; Barrette, J.; Laganière, J.; Mabee, W.; Paré, D.; Gautam, S.; Thiffault, E.; Ghafghazi, S. Salvage harvesting for bioenergy in Canada: From sustainable and integrated supply chain to climate change mitigation. Wiley Interdiscip. Rev. Energy Environ. 2018, 7, e298. [CrossRef]

40. McGregor, D. Aboriginal/Non-Aboriginal Relations and Sustainable Forest Management in Canada: Ten years since the Royal Commission. J. Environ. Manag. 2011, 92, 3000-3010. [CrossRef]

41. Smith, D.W.; Bibeau, E.L.; Tampier, M. Community-Based Model for Forest Land Management and Bioenergy Production Using a Distributed CHP System. 2006. Available online: http://home.cc.umanitoba.ca/ $\sim\{$ bibeauel/research/papers/2006_Bibeau_bioenergy2006.pdf (accessed on 3 March 2010).

42. Berkes, F.; Berkes, M.K.; Fast, H. Collaborative integrated management in Canada's north: The role of local and traditional knowledge and community-based monitoring. Coast. Manag. 2007, 35, 143-162. [CrossRef]

43. Sandlos, J.; Keeling, A. Aboriginal communities, traditional knowledge, and the environmental legacies of extractive development in Canada. Extr. Ind. Soc. 2016, 3, 278-287. [CrossRef]

44. Cooke, S.J.; Rice, J.C.; Prior, K.A.; Bloom, R.; Jensen, O.; Browne, D.R.; Donaldson, L.A.; Bennett, J.R.; Vermaire, J.C.; Auld, G. The Canadian context for evidence-based conservation and environmental management. Environ. Evid. 2016, 5, 14. [CrossRef]

45. Mansuy, N.; Burton, P.J.; Stanturf, J.; Beatty, C.; Mooney, C.; Besseau, P.; Degenhardt, D.; MacAfee, K.; Lapointe, R. Scaling up forest landscape restoration in Canada in an era of cumulative effects and climate change. For. Policy Econ. 2020, 116, 102177. [CrossRef]

Publisher's Note: MDPI stays neutral with regard to jurisdictional claims in published maps and institutional affiliations.

(C) 2020 by the authors. Licensee MDPI, Basel, Switzerland. This article is an open access article distributed under the terms and conditions of the Creative Commons Attribution (CC BY) license (http://creativecommons.org/licenses/by/4.0/). 